\title{
Comment \\ Medically Unexplained Symptoms (MUS): Faults and Implications
}

\author{
Michiel Tack $+(1)$ \\ Sint-Laurentiusstraat 87, 9700 Oudenaarde, Belgium; tackmichiel@gmail.com \\ + Independent researcher.
}

Received: 13 March 2019; Accepted: 3 April 2019; Published: 8 April 2019

\begin{abstract}
The classification of medically unexplained symptoms (MUS) could have negative consequences for patients with functional somatic syndromes (FSS). By grouping related but distinct syndromes into one label, the MUS classification fails to inform clinicians about their patients' health condition. In research settings, the MUS classification makes patient samples more heterogeneous, obstructing research into the underlying pathology of FSS. Long-term studies have shown that MUS are often appraised as medically explained symptoms at follow-up and vice versa, raising doubts about the reliability of this distinction.
\end{abstract}

Keywords: medically unexplained symptoms (MUS); functional somatic syndromes (FSS); chronic fatigue syndrome (CFS); fibromyalgia; somatic symptom disorder (SSD)

In their recent paper, Guo et al. evaluate commonalities across medically unexplained symptoms (MUS) [1]. The justification of this classification has not been adequately discussed in the scientific literature.

The main argument for MUS is the significant symptom overlap across several medically unexplained syndromes. According to Guo et al. [1], a patient with unexplained fatigue and widespread pain might be diagnosed with chronic fatigue syndrome (CFS), fibromyalgia (FM) or somatic symptom disorder (SSD) depending on the clinical setting. While correct, this diagnostic overlap is mostly a consequence of how these syndromes have been defined. FM, for example. "remains a valid construct irrespective of other diagnoses" [2]. This means a CFS patient can be diagnosed with comorbid FM without diagnostic confusion. In a community-based sample, $15 \%$ of CFS patients also met diagnostic criteria for FM [3]. Similar rates have been found in rheumatic conditions such as systemic lupus erythematosus (SLE) or rheumatoid arthritis (RA), indicating that this diagnostic overlap is not restricted to functional somatic syndromes [4]. Studies have shown that CFS patients with comorbid FM have more impairments [5,6] and a worse prognosis [7] than CFS patients without FM. The influence of comorbid FM on the prognosis of CFS persists after controlling for multiple nonspecific symptoms. This is inconsistent with the hypothesis that CFS and FM represent different manifestations of a single underlying syndrome. While CFS and FM are related conditions, research has indicated biological differences between the two [8,9].

A patient with CFS or FM might also be diagnosed with SSD. This is a consequence of the broad SSD criteria defined in the fifth edition of the Diagnostic and Statistical Manual of Mental Disorders (DSM-V), which, according to some commentators, "open the floodgates to the over-diagnosis of mental disorder" [10]. The diagnosis of SSD merely requires that a persistent physical symptom is accompanied by disproportionate health-related thoughts and behaviors [11]. While the definition of somatization disorder in the DSM-IV required a history of multiple medically unexplained symptoms before the age of 30, the diagnosis of SSD can essentially be made when a patient worries excessively about his or her medical condition. Consequently, patients with CFS or FM might be diagnosed with 
SSD, yet the same is true for "explained" medical conditions such as RA, SLE or liver cirrhosis [12]. Instead of questioning the legitimacy of CFS or FM, a large diagnostic overlap with SSD challenges the DSM-V case definition as it risks mislabelling patients as mentally ill. Empirical research has questioned the validity of SSD in patients with functional somatic syndromes such as FM [13].

If the main difficulty faced by clinicians is diagnostic confusion and a need for better differentiation between functional somatic syndromes, then stricter diagnostic criteria seem warranted. Disregarding all differences between these health conditions by creating one large MUS classification will reinforce rather than solve this problem. CFS offers an example that a more accurate case definition does not necessarily require a better understanding of the underlying pathology. Instead of fatigue, the hallmark symptom of CFS is now considered to be post-exertional malaise (PEM), a significant symptom exacerbation each time patients exceed their current energy limit [14]. PEM helps clinicians to differentiate CFS patients from patients with idiopathic chronic fatigue [15] or multiple sclerosis [16] and predicts a worse prognosis [17].

While the benefits of the MUS classification are unclear, the risks and faults are evident. Due to PEM, CFS patients might respond differently to an exercise regime than patients with pain syndromes [18]. By grouping both types of patients into one clinical entity, MUS fails to provide therapists with the necessary information to offer the most adequate care.

Similar problems might arise in research settings. By making patient samples more heterogeneous, MUS risks obstructing research into the underlying pathology of functional somatic syndromes. Throughout medical history, the trend has been towards subgrouping and better differentiation of seemingly similar health conditions. Cancer, for example, was once considered to be a single disease but is now divided into multiple clinical entities [19]. A similar evolution can be found in current research on Alzheimer's disease [20] or SLE [21]. The MUS classification seems to be an anachronistic exception to this rule.

If up to $50 \%$ of patients in hospital-based care have MUS, as Guo et al. [1] claim, one might question whether anything useful can be said about the etiology of such a broad and heterogeneous group of patients. No reason has been provided for why the numerous health complaints modern medicine fails to explain would have anything in common. The common factor between MUS patients seems to be the limitations of our medical technology and understanding, rather than the underlying condition of these patients. Additionally, MUS are often appraised as medically explained symptoms at follow-up and vice versa, raising doubts about the reliability of this distinction [22,23].

Finally, Guo et al.'s claim that correcting misinterpretations of somatic sensations could be seen as a preventive strategy of MUS is a contradiction in terms. If the authors truly believe that misinterpretations of ordinary somatic sensations are responsible for MUS, then they should not label these symptoms as unexplained but instead as psychiatric.

Funding: This research received no external funding.

Conflicts of Interest: The authors declare no conflict of interest.

\section{References}

1. Guo, D.; Kleinstäuber, M.; Johnson, M.H.; Sundram, F. Evaluating Commonalities across Medically Unexplained Symptoms. Int. J. Environ. Res. Public Health 2019, 16, 818. [CrossRef]

2. Wolfe, F.; Smythe, H.A.; Yunus, M.B.; Bennett, R.M.; Bombardier, C.; Goldenberg, D.L.; Tugwell, P.; Campbell, S.M.; Abeles, M.; Clark, P.; et al. The American College of Rheumatology 1990 Criteria for the Classification of Fibromyalgia. Report of the Multicenter Criteria Committee. Arthritis Rheumatol. 1990, 33, 160-172. [CrossRef]

3. Jason, L.A.; Taylor, R.R.; Kennedy, C.L. Chronic fatigue syndrome, fibromyalgia, and multiple chemical sensitivities in a community-based sample of persons with chronic fatigue syndrome-like symptoms. Psychosom. Med. 2000, 62, 655-663. [CrossRef] [PubMed] 
4. Yunus, M.B. The prevalence of fibromyalgia in other chronic pain conditions. Pain Res. Treat. 2012, 2012, 584573. [CrossRef] [PubMed]

5. Schmaling, K.B.; Betterton, K.L. Neurocognitive complaints and functional status among patients with chronic fatigue syndrome and fibromyalgia. Qual. Life Res. 2016, 25, 1257-1263. [CrossRef]

6. Meeus, M.; Ickmans, K.; Struyf, F.; Kos, D.; Lambrecht, L.; Willekens, B.; Cras, P.; Nijs, J. What is in a name? Comparing diagnostic criteria for chronic fatigue syndrome with or without fibromyalgia. Clin. Rheumatol. 2016, 35, 191-203. [CrossRef]

7. Ciccone, D.S.; Chandler, H.K.; Natelson, B.H. Illness trajectories in the chronic fatigue syndrome: A longitudinal study of improvers versus non-improvers. J. Nerv. Ment. Dis. 2010, 198, 486-493. [CrossRef]

8. Abbi, B.; Natelson, B.H. Is chronic fatigue syndrome the same illness as fibromyalgia: Evaluating the 'single syndrome' hypothesis. QJM 2013, 106, 3-9. [CrossRef]

9. $\quad$ Evengard, B.; Nilsson, C.G.; Lindh, G.; Lindquist, L.; Eneroth, P.; Fredrikson, S.; Terenius, L.; Henriksson, K.G. Chronic fatigue syndrome differs from fibromyalgia. No evidence for elevated substance $\mathrm{P}$ levels in cerebrospinal fluid of patients with chronic fatigue syndrome. Pain 1998, 78, 153-155. [CrossRef]

10. Frances, A.; Chapman, S. DSM-5 somatic symptom disorder mislabels medical illness as mental disorder. Aust. N. Z. J. Psychiatry 2013, 47, 483-484. [CrossRef] [PubMed]

11. Dimsdale, J.E.; Creed, F.; Escobar, J.; Sharpe, M.; Wulsin, L.; Barsky, A.; Lee, S.; Irwin, M.R.; Levenson, J. Somatic symptom disorder: An important change in DSM. J. Psychosom. Res. 2013, 75, 223-228. [CrossRef]

12. Häuser, W.; Wolfe, F. The Somatic Symptom Disorder in DSM 5 risks mislabelling people with major medical diseases as mentally ill. J. Psychosom. Res. 2013, 75, 586-587. [CrossRef] [PubMed]

13. Häuser, W.; Bialas, P.; Welsch, K.; Wolfe, F. Construct validity and clinical utility of current research criteria of DSM-5 somatic symptom disorder diagnosis in patients with fibromyalgia syndrome. J. Psychosom. Res. 2015, 78, 546-552. [CrossRef]

14. Institute of Medicine. Beyond Myalgic Encephalomyelitis/Chronic Fatigue Syndrome: Redefining an Illness; The National Academies Press: Washington, DC, USA, 2015.

15. Maes, M.; Twisk, F.N.; Johnson, C. Myalgic Encephalomyelitis (ME), Chronic Fatigue Syndrome (CFS), and Chronic Fatigue (CF) are distinguished accurately: Results of supervised learning techniques applied on clinical and inflammatory data. Psychiatry Res. 2012, 200, 754-760. [CrossRef]

16. Cotler, J.; Holtzman, C.; Dudun, C.; Jason, L.A. A Brief Questionnaire to Assess Post-Exertional Malaise. Diagnostics 2018, 8, 66. [CrossRef] [PubMed]

17. Taylor, R.R.; Jason, L.A.; Curie, C.J. Prognosis of chronic fatigue in a community-based sample. Psychosom. Med. 2002, 64, 319-327. [CrossRef]

18. Geraghty, K.; Hann, M.; Kurtev, S. Myalgic encephalomyelitis/chronic fatigue syndrome patients' reports of symptom changes following cognitive behavioural therapy, graded exercise therapy and pacing treatments: Analysis of a primary survey compared with secondary surveys. J. Health Psychol. 2017. [CrossRef]

19. Mukherjee, S. The Emperor of all Maladies: A Biography of Cancer; Simon \& Schuster: New York, NY, USA, 2010.

20. Mukherjee, S.; Mez, J.; Trittschuh, E.H.; Saykin, A.J.; Gibbons, L.E.; Fardo, D.W.; Wessels, M.; Bauman, J.; Moore, M.; Choi, S.E.; et al. Genetic data and cognitively defined late-onset Alzheimer's disease subgroups. Mol. Psychiatry 2018. [CrossRef]

21. Agmon-Levin, N.; Mosca, M.; Petri, M.; Shoenfeld, Y. Systemic lupus erythematosus one disease or many? Autoimmun. Rev. 2012, 11, 593-595. [CrossRef] [PubMed]

22. Leiknes, K.A.; Finset, A.; Moum, T.; Sandanger, I. Methodological issues concerning lifetime medically unexplained and medically explained symptoms of the Composite International Diagnostic Interview: A prospective 11-year follow-up study. J. Psychosom. Res. 2006, 61, 169-179. [CrossRef]

23. Klaus, K.; Rief, W.; Brähler, E.; Martin, A.; Glaesmer, H.; Mewes, R. The distinction between "medically unexplained" and "medically explained" in the context of somatoform disorders. Int. J. Behav. Med. 2013, 20, 161-171. [CrossRef]

(c) 2019 by the author. Licensee MDPI, Basel, Switzerland. This article is an open access article distributed under the terms and conditions of the Creative Commons Attribution (CC BY) license (http:// creativecommons.org/licenses/by/4.0/). 